\title{
Relation between Spirals in Pre-Hispanic Design with Mathematics Spirals
}

\author{
José Luis Mamaní \\ Graduated from Faculty of Engineering, National University of Jujuy-Argentina.
}

Received: May 12, 2015 / Accepted: June 09, 2015 / Published: October 25, 2015.

\begin{abstract}
The spiral has been studied for the first time in the book "About the spirals", by Archimedes (Greece, 287-212 BC). In America, the design of spirals seems to have been used previous to Archimedes' time, although in the Northwest of Argentina the appearance of this figure in ceramics can be dated between the years 800 and 1,400 (AD). The spiral is found in cave paintings, in pumpkin carvings and in pottery, particularly those painted inside of plates (pucos in Quechua language). There can be seen simple linear spirals, double spirals and spirals filled with squares, spirals in two, facing each other symmetrically, as well as spirals joined to bodies of animals. The number of spires detected in the largest spiral is 12 , a number of evidently sacred characteristics. When there are several spirals in an earthenware vessel, it can be seen that all of them spin to the same side whether it is clockwise or not. This could have been caused by the predominance of the use of either one hand or the other by the ancient artist. This paper is produced with computer methods used to design spirals in the computer, either Archimedes or the logarithmic ones. Finally, the book: "Man and his symbols" of the psychiatrist Carl Gustav Jung (1875-1961) help to understand this congruencies. In this paper, Mathematics is complemented with the Archeology of art and Psychology.
\end{abstract}

Key words: Spirals, complementarity, art, conscience, unconscious.

\section{Introduction}

This paper is a chapter of the book: "Geometry in Pre-Hispanic Pottery" edited in Spanish in 2009, by the National University of Jujuy-Argentina, written by the undersigned. It is an interdisciplinary work, archaeological-mathematical, basically.

From the mathematical point of view, concepts are applied from this science to the spiral, since exist a notable similitude between pre-Columbian spirals and academic geometric shapes.

The concept of "geometric shapes" in pre-Columbian archaeological material, lead to these questions: Which is the relation with academic geometry in these shapes? How is seen a shape like the spiral from the mathematical and pre-Columbian point of view? All that, in order to get closer to a

Corresponding author: Jose Luis Mamani, Bachelor in Mathematics Teaching, research field: Ethno mathematics in the Andean culture in South America. Email: lito2691@gmail.com. better and more correct interpretation of them, thinking that both perspectives refer to a "Unique World", term used by the Swiss psychologist and psychiatrist, Carl Jung (1875-1961).

\section{Materials and Methods}

Pre-Hispanic ceramic material has been registered at museums in La Quebrada de Humahuaca - Jujuy Argentina. Then, History texts of Mathematics has been resorted, to situate in time the spiral origin and its concept, and in this way a parallelism between geometric shapes of the Occidental Mathematics History and pre-Columbian geometric shapes.

\section{Results and Discussion}

\subsection{Spirals in Mathematics History}

"About the spirals" is the title of one of the books of flat Geometry of Archimedes (Greek mathematician 287-212 B.C.), who studied this figure 
and to whom is attributed the term "spiral".

Archimedes is the most scientist of all Greeks, the wisest mathematician of the classical antiquity; he is the first who realized that the exterior world (the nature) is the deepest source from which flows all knowledge.

Some contemporaries of Archimedes asked about him: Is he a magician? Is he a madman, a demon or both? "About the spirals" is one of the most difficult Archimedes texts. During XVII and XVIII centuries there were mathematicians that desisted from understanding him and also some of them preferred consider wrong the Archimedes' work. Analytic Geometry and Infinitesimal Analysis have facilitated the acquisition of these results, fact that enhanced Archimedes' merits.

Archimedes' Spiral: (See Fig 1). The curve start from pole $\mathrm{O}$ and can be considered generated by a dot that moves with constant angular speed.

Spire: is each spin of the spiral, for example, the following is a spiral of two spires. Beginning in the center (Fig 1), Archimedes' spiral turn in anticlockwise direction.

Evangelista Torricelli (1608 - 1647) studied logarithmic spirals.

The "spira mirabilis" (wonderful spiral) thus called the logarithmic or growing spiral by the famous Swiss mathematician Jacob Bernoulli (1654-1705). Among other elements he considered that the self-resemblance, that is to say, the fact of seem the same, the spiral, in any scale, was the biggest marvel.

This curve is a mathematical symbol of the relation between shape and growth, that is why its name.

The logarithmic spiral have interested mathematicians and artists equally.

Function in polar coordinate of the logarithmic spiral: $r=e^{a \varphi}$

Also exist the hyperbolic spiral and spherical or loxodromic spiral thus called by the Dutch mathematician Snellius de Roijen (1591-1626), the latter on a spherical surface.

\subsection{The Spiral as Fractal.}

The word fractal was introduced in 1980 by the Polish mathematician Berroit B. Mandelbrot, who was born in Warsaw in 1924. Fractal comes from the Latin adjective "fractus", that means interrupted or irregular.

Mandelbrot brought the fractal geometry of the nature in the world. And, what is the fractal geometry? Is first of all a new language. In the same way the elements of the Euclidian Geometry are dots, lines, circles, etc. The elements of the fractal Geometry escape from the direct perception. That is due to they are algorithms that just in a computational way can be expressed in shapes and structures. Mandelbrot's essence of the message is that a lot of natural structures, with an apparent complexity (for example: clouds, mountains, coast, tectonic faults, vascular



Fig. 1 Archimedes' Spiral: $r=a \varphi, r \geq 0, a>0, \varphi \geq 0$. 




Fig. 2 The Logarithmic Spiral.

systems, fractured surfaces of materials etc.) are characterized by an invariant geometric scale, which fractal dimension provides an adequate mathematical description of the phenomenon.

Is it the former, perhaps, a re-harmonization of the Mathematics with the nature.

\section{Examples:}

If it is increased considerably the number of spires in Archimedes spiral it will be obtained figures 3 and 4:

The former is similar to some pre-Hispanic lineal spirals, for example with the spirals of pictures 4 and 5 (See photography section at the end).

The spiral has been marked to show its shape similitude and its reticulated design, with spiral figures in pre-Columbian pottery, for example with pictures 1 and 2 at the end of the text. Using Jung's concepts, would be cases of "synchronicity" or "significant coincidence" that are not connected by chance, and point out a unitary idea of the reality, - the unique world -

The symbols are natural attempts to reconcile and join opposites inside human psyche: the mathematical-conscious-rational and the shamanic ${ }^{1}$ intuitive -unconscious.

\subsection{Spirals Joined to Animals Bodies.}

The spirals are a constant in the iconography of the

\footnotetext{
1 Shaman: aborigine, intermediary between the inaccessible divinity and the common people.
}

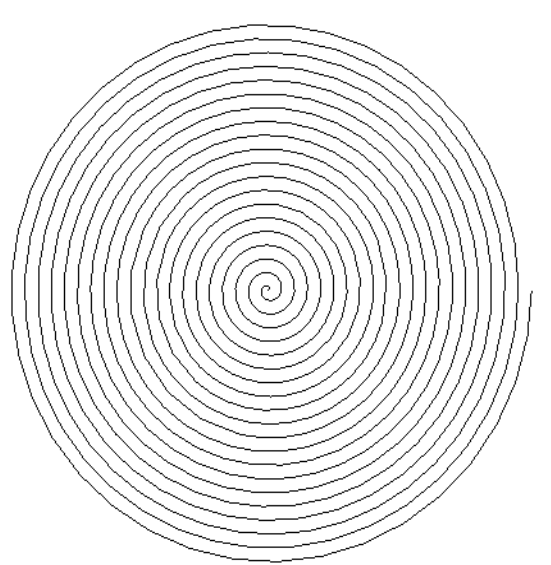

Fig. 3 Archimedes' Spiral as fractal.

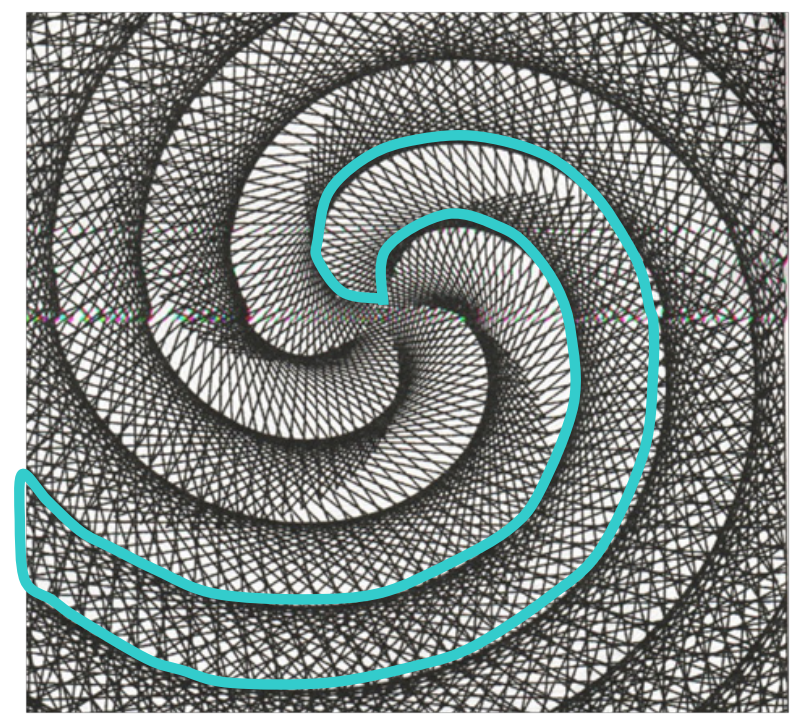

Fig. 4 Archimedes' spiral as fractal.

pre-Columbian ceramic in America, also appears in the world cave painting art. In particular in, la Quebrada de Humahuaca-Jujuy-Argentina is repetitive the union of the spiral to zoo-anthropomorphic bodies, for example in Inca Cueva, an archaeological site that contains numerous cave paintings, dated between 10000-9000 B.C.

The spiral was enhanced in the Geoglyphe: Nazca Monkey, in Peru (Nazca culture 0-700 A.D.) These works drawn in a surface about $450 \mathrm{~km}^{2}$, have amazed the scientists in such a way that some of them attributed this work to "extraterrestrials". It is supposed that they were made with a ceremonial and astronomical character. 


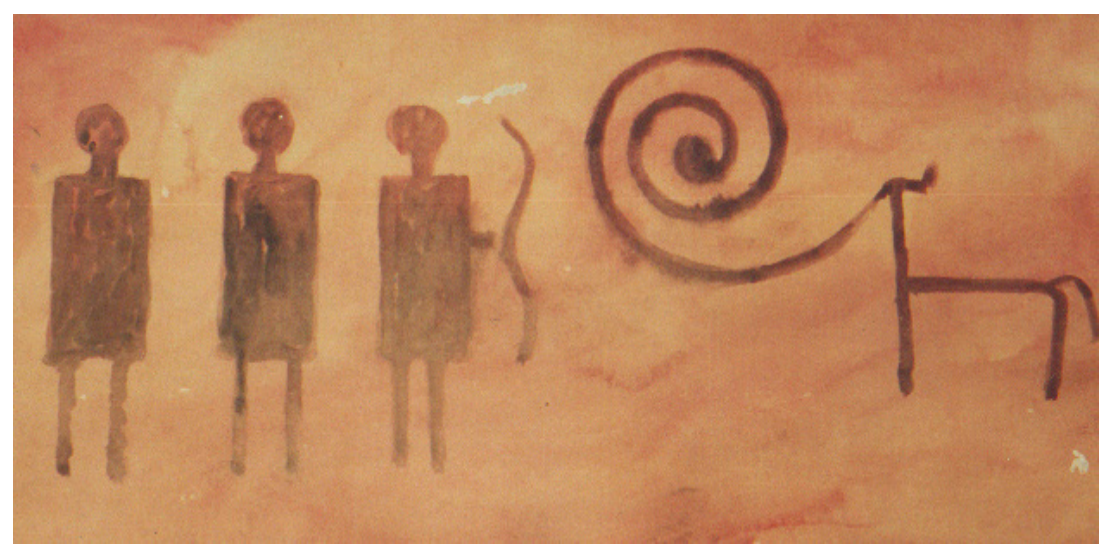

Fig. 5 Idealized photomontage, inspired in paintings in Inca Cueva, by Pellegrini. Archaeological Museum, Jujuy Argentina.

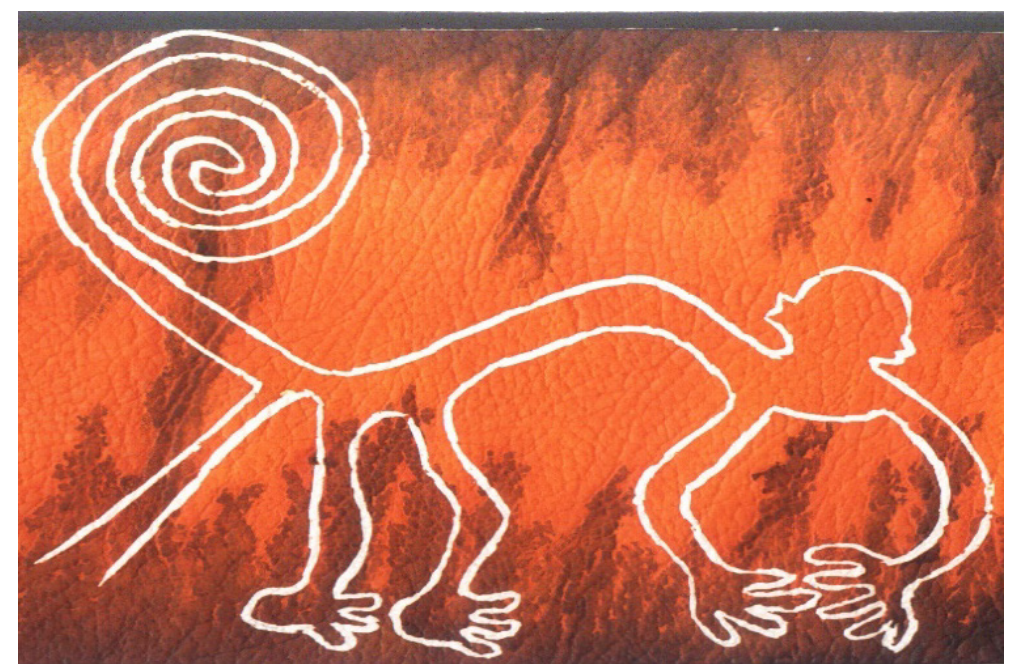

Fig. 6 Geoglyphe: Spiral in two dimensions in the Nazca - Peru monkey's tail. Anonymous artistic representation.

The spiral, is in both sides of the Atlantic ocean, before 1942, on the one hand the intellectual work of this figure made by Archimedes and other mathematicians, on the other the enhanced figure in Nazca, an icon in the Andean culture and other cultures of the world, so the spiral is a universal symbol, for the effort made in it by people of different geographic and temporal spaces.

The figure with spiral shape related with divinities that also appear in contemporary people's dreams.

\subsection{Spirals in Contemporary Visions.}

It is very important the Jung's psychology participation, for a better icons interpretations, since he writes:

"...when it is desired to search man's faculty to create symbols, dreams are the basic and accessible material to do it...what we cannot perceive consciously, often the unconscious can see it, and it is possible to analyze the content through dreams.

We cannot allow ourselves of being naive when treating dreams. Dreams are originated in a spirit which is not totally human, but in a nature manifestation, a spirit of beautiful and generous goddesses, also cruel. If we want to characterize this spirit, we will have to get closer it, get closer to ancient mythologies or primitive forest fables, that in the conscience of the modern man... To benefit the mental stability and also the health psychology, the unconscious and the conscious have to be connected integrally and, therefore move in parallel direction."

Dream tales that Jung gives as example in his book 
"Man and his symbols" and its relation with the spiral figure:

- "A painting made by a simple woman, who had lived her childhood in a protestant environment, showed a mandala ${ }^{2}$ shaped in spiral. In a dream, this woman was told to paint the Divinity. Afterwards (in a dream too) she was seen in a book. Of God himself she saw his tunic fluttering, and a display of light and shadow from his clothes. This contrasted in an impressive way with the spiral stability, in the firmament depth. Fascinated by the tunic and the spiral the dreamer did not watch thoroughly the other figure that was on the rocks. When she woke up and thought about the divine figures, she suddenly realized, that was "God himself". That caused her a commotion, fear that last in her a long time." (Jung, 1984:224)

- "Something flies, got in through the window, similar to an insect with twisted legs in spiral, yellow and black, like a tiger, bear's legs almost human and a sharped face like a wolf...But I see that creature half woman, half animal ..." (Jung, 1984;139).

\section{Conclusions}

Is the spiral a Divine image?

The spiral is a symbol ${ }^{3}$, an archetype ${ }^{4}$ that last in time:

The Andean aborigine had it (the spiral) present in their icons from their first abstract representations on the rocks, always looking for the Universe secret symbols that are not seen directly, and they probably did it in a state of ecstasy or trance, perhaps caused by phoshen $^{5}$ or those symbols were left as inheritance by world archaic minds.

\footnotetext{
2 Mandala: Hindu word adopted by Jung (magic circle). Is a symbolic representation of the "nuclear atom" that belongs to the human psyche, which essence is unknown.

3 Symbol: is an object of the known world, suggesting something that is unknown, is the known expressing the life and sense of the inexpressible.

${ }^{4}$ Archetypes. Are symbolic images that have not a known origin and are produced at any time or in any part of the world.

5 Phosphen: (from the Greek phôs, light and phaino, to bright). Luminous sensation that takes place when eyes are closed and happen a sudden compression.
}

Archimedes, found the first mathematical formulas that allowed to draw a spiral in a plane and studied in it numerous properties. Then, other mathematicians discovered another formulae that being transferred to a system of Cartesian axes give as result diverse spirals.

Nowadays the spiral is found in fractal graphics, being the latter a new science. Some mathematicians affirm that the figures are not invented, but discovered by them, and with that exposition we could say that the spiral is part of the Universe Sacred Geometry.

Spirals ancestral figures are bonded with mathematical spirals, and with contemporary oral tales about dreams, bearing in mind that:

If we want to see the things in their true perspective, it is necessary to understand the past and present. That is why the essential of understanding myths and symbols.

The spiral would be one of these old and true symbols that far of being dead, try to reborn in a modern way.

If we go more far, our galaxy, the Milky Way is a spiral galaxy in which the Solar System is, and where we live.

\section{References}

[1] Fernández Chiti, Jorge, La simbólica en la cerámica indígena argentina. Tomos1 y 2. Ediciones Condorhuasi, Buenos Aires, Argentina, 1998.

[2] Fernández Distel, Alicia, Arte rupestre cerca del cielo. cd - rom. 2003.

[3] Fernández Distel, Alicia, Iconografía prehispánica de Jujuy: una visión desde la arqueología, Editorial Dunken, Buenos Aires, Argentina, 2004.

[4] Fernández, Jorge, Algunas expresiones estilísticas del arte rupestre de los andes de Jujuy, En: M. Podestá y M. de Hoyos (Ed.), Arte en las rocas, Sociedad Argentina de Antropología y Asociación de Amigos del INAPL, Buenos Aires, Argentina, 2000.

[5] Jung, Carl, El hombre y sus símbolos, Editorial Biblioteca Universal Contemporánea, Barcelona, España, 1984. $4^{\circ}$ edición.

[6] Mamaní, José Luis, Geometría en Cerámica Prehispánica, Editorial UNJu, Jujuy, Argentina, 2009.

[7] Nielsen, Axel y Lucio Boschi, Quebrada de Humahuaca un itinerario cultural con 10.000 años de historia, 
CFI.Gobierno de Jujuy-Argentina, 2004.2 Edición.

[8] Rey Pastor J. y Babini J., Historia de la Matemática, Espasa Calpe Argentina. SA. Buenos Aires, 1951

[9] Sarasola Martínez, C. y Llamazares A.M., El lenguaje de los dioses. Arte, chamanismo y cosmovisión indígena en Sudamérica, Editorial Biblos, Buenos Aires, Argentina.
2004. $1^{\text {oedición. }}$

[10] Vera, Francisco, Breve historia de la Geometría, Editorial Losada SA., Buenos Aires, Argentina, 1948.

[11] Vera de Spinadel, Perera Jorge G. y Perera Jorge H., Geometría Fractal, Editorial Nueva Librería, Buenos Aires, Argentina, 1994. $1^{\circ}$ edición.

Pictures from Archaeological Museum of Tilcara, Jujuy, Argentina.



Picture 1. Ceramic 3255.

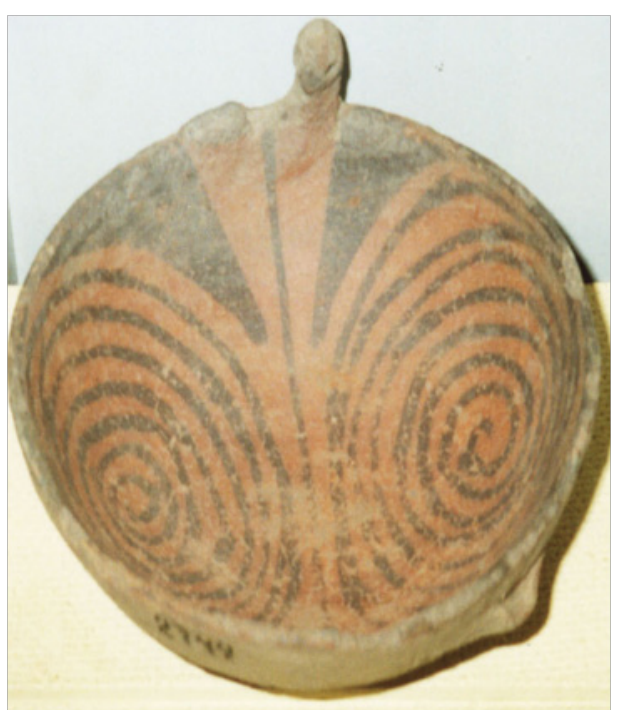

Picture 4. Ceramic 2749. Period: $850-1480$ A.D. Spirals with seven spires each, with end apparently closed.



Picture 2. Spiral in pre-Hispanic ceramic.

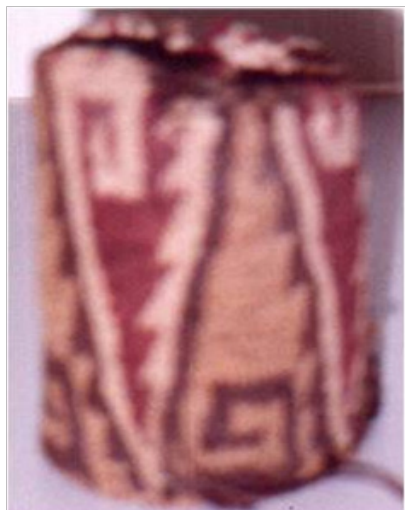

Picture 3. Spiral in quadrangular design in knitted wristband.

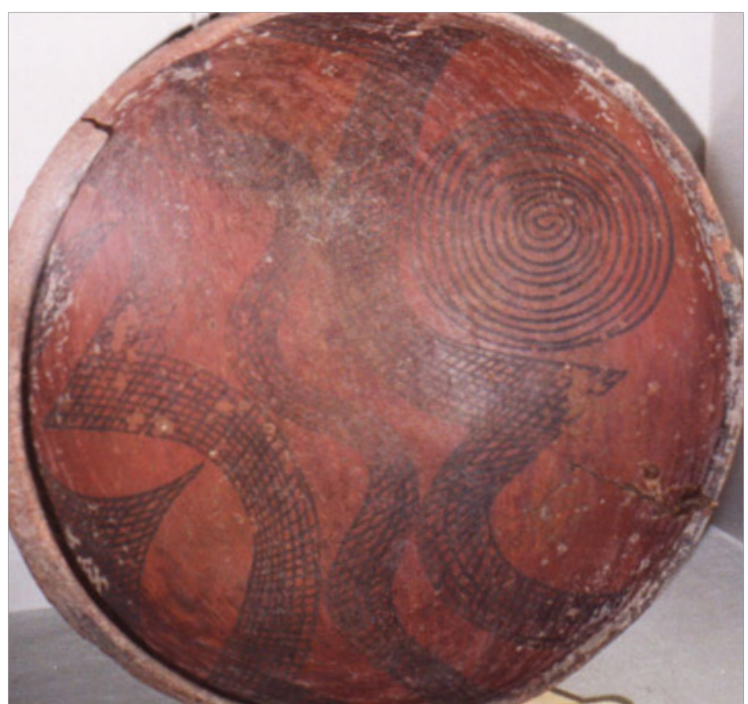

Picture5. Períod: $850-1480$ A.D. Spiral with twelve spires at the top. 